\title{
Teses e DissertaçÕes
}

Maio a setembro de 2004

\section{Teses}

\section{GUILLAH NASLAVSKY}

Arquitetura moderna em Pernambuco 1951- 1972.

As contribuições de Acácio Gil Borsoi e Delfim

$\frac{\text { I64 }}{\text { வ் }}$

Fernandes Amorim

Data: 03.05.04

Orientador(a): Prof. Dr. Carlos Alberto Cerqueira
Lemos

\section{SUN ALEX}

Convívio e exclusão no espaço público: Questões de projeto da praça

Data: 27.05 .04

Orientador(a): Profa. Dra. Miranda Maria Esmeralda

Martinelli Magnoli

ANA CRISTINA FERNANDES VAZ MILHEIRO

Imenso Portugal culturas arquitetônicas portuguesa

e brasileira um diálogo a três tempos

Data: 22.06 .04

Orientador(a): Prof. Dr. João Walter Toscano

ANDRÉA DE OLIVEIRA TOURINHO

Do centro aos centros: Bases teórico-conceituais para o estudo da centralidade em São Paulo

Data: 28.06 .04

Orientador(a): Profa. Dra. Maria Irene Szmrecsanyi

\section{ANA MARIA ANTUNES COELHO}

$O$ outro lado da rua

Data: 01.07.04

Orientador(a): Profa. Dra. Miranda Maria Esmeralda Martinelli Magnoli

\section{MARISTELA MITSUKO ONO}

Design industrial e diversidade cultural: Sintonia essencial. Estudos de casos nos setores

automobilístico, moveleiro e de eletrodomésticos no Brasil

Data: 04.08.04

Orientador(a): Profa. Dra. Maria Cecília Loschiavo dos Santos

NEYDE ANGELA JOPPERT CABRAL

A Universidade de São Paulo: Modelos e projetos Data: 09.08.04

Orientador(a): Prof. Dr. Dácio Araújo Benedicto

Ottoni

\section{DANIELA MARTINS BÜCHLER}

Louça de mesa da indústria brasileira: Produto e produtor

Data: 10.08 .04

Orientador(a): Prof. Dr. Rafael Antonio Cunha

Perrone

\section{MIRIAM NOHEMY MEDINA VELASCO}

Descentralização e política urbana em municípios de porte médio: Os casos de Alagoinhas e Barreiras na Bahia

Data: 16.08 .04

Orientador(a): Profa. Dra. Rebeca Scherer

\section{MARIA PRONIN}

Interação do edifício com o ambiente urbano do espaço privado para o espaço público

Data: 20.08 .04

Orientador(a): Prof. Dr. Siegbert Zanettini 


\section{PAULO ROMANO RESCHILIAN}

A produção de assentamentos precários em São José dos Campos: A favela Nova Tatetuba, um exemplo para análise

Data: 23.08.04

Orientador(a): Profa. Dra. Erminia T. M. Maricato

\section{NILSON FRANCO MARTINS}

A hierarquização viária como tecnologia para as interfaces urbano-rodoviárias

Data: 10.09 .04

Orientador(a): Prof. Dr. José Jorge Boueri Filho

\section{TEREZINHA DE OLIVEIRA GONZAGA}

A cidade e a arquitetura também mulher:

Conceituando a metodologia de planejamento urbano e dos projetos arquitetônicos do ponto de vista de gênero

Data: 16.09 .04

Orientador(a): Profa. Dra. Marlene Yurgel

\section{REGINA CUNHA WILKE}

A dimensão do encantamento: Cenografia e tecnologias digitais

Data: 20.09 .04

Orientador(a): Profa. Dra. Élide Monzeglio

\section{Dissertações}

\section{JOSÉ CARLOS MENDES ANDRÉ}

Elementos para uma leitura da obra de Aparício Torelli, o barão de Itararé: Humor, projeto \& design gráfico

Data: 20.05 .04

Orientador(a): Prof. Dr. Rafael Antonio Cunha

Perrone

\section{ROBERTO ISRAEL EISENBERG SARUÊ}

O Aeroporto de Congonhas e a cidade de São Paulo Data: 26.05 .04

Orientador(a): Prof. Dr. Candido Malta Campos Filho

\section{PAULO EDUARDO MORETTO}

Cartazes de propaganda cultural no Brasil cinco décadas de técnicas e linguagem

Data: 01.07.04

Orientador(a): Prof. Dr. Luís Antonio Jorge

\section{LUCIANO TORRES TRICÁRICO}

Modernidade e imagem urbana: Raptos de cidade na metrópole

Data: 23.07.04

Orientador(a): Profa. Dra. Lucrécia D’Alessio Ferrara

\section{MARIA CECÍLIA LUCCHESE}

Curam-se cidades uma proposta urbanística da década de 70

Data: 09.08.04

Orientador(a): Prof. Dr. Antonio Cláudio M. Lima e Moreira pós- 


\section{LUCIANA BOM DUARTE FANTINI}

Arquitetura hoteleira: Avaliação de duas categorias na cidade de São Paulo. Elementos para a montagem de um método de projeto

Data: 12.08 .04

Orientador(a): Prof. Dr. Wilson Edson Jorge

\section{FERNANDA BÁRBARA}

O conjunto Ana Rosa e o Edifício Copan. Contexto e análise de dois projetos realizados em São Paulo nos anos 50

Data: 20.08.04

Orientador(a): Profa. Dra. Regina Maria Prosperi

Meyer

\section{SILVANA SERAFINO CAMBIAGHI}

Desenho universal: Métodos e técnicas de ensino na graduação de arquitetos e urbanistas

Data: 25.08 .04

Orientador(a): Profa. Dra. Sheila Walbe Ornstein

\section{MANOELA ROSSINETTI RUFINONI}

Preservação do patrimônio industrial na cidade de São Paulo: O bairro da Mooca

Data: 13.09 .04

Orientador(a): Profa. Dra. Beatriz Mugayar Kühl

\section{MÁRCIA SAEKO HIRATA}

Formação do espaço e espaço da formação. Contexto e prática do projeto participativo na RMSP Data: 14.09 .04

Orientador(a): Profa. Dra. Maria Cecília Loschiavo dos Santos

\section{CRISTIANE SOUZA GONÇALVES}

Metodologia para a restauração arquitetônica: A experiência do serviço do patrimônio histórico e artístico nacional em São Paulo, 1937-1975

Data: 23.09 .04

Orientador(a): Profa. Dra. Maria Lucia Bressan

Pinheiros

\section{GABRIELA DE GUSMÃO PEREIRA}

Sobre projetar e sobreviver na rua - Um inventário de inventos

Data: 24.09 .04

Orientador(a): Profa. Dra. Maria Cecília Loschiavo dos Santos

\section{PEDRO FIORI ARANTES}

O ajuste urbano: As políticas do Banco Mundial e do BID para as cidades latino-americanas

Data: 24.09.04

Orientador(a): Profa. Dra. Erminia T. M. Maricato

\section{LUCIANA TOMBI BRASIL}

A obra de David Libeskind. Ensaio sobre as residências unifamiliares

Data: 24.09 .04

Orientador(a): Prof. Dr. Luís Antonio Jorge

MARIA DA GRAÇA PLENAMENTE SILVA

A "irregularidade" na produção de conjuntos habitacionais de interesse social: O caso da Cohab-SP Data: 28.09.04

Orientador(a): Profa. Dra. Marta Dora Grostein 